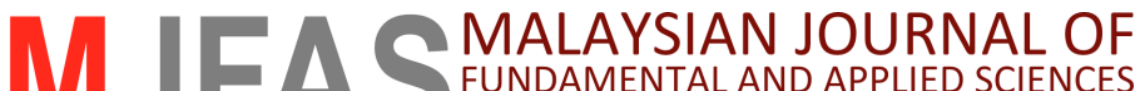 FUNDAMENTAL AND APPLIED SCIENCES PRINT ISSN: 2289-5981 | ONLINE ISSN: 2289-599X
}

\section{Synthesis and characterization of zeolite NaX from Bangka Belitung Kaolin as alternative precursor}

\author{
Vita Nur Iftitahiyah a, Didik Prasetyoko ${ }^{\text {a, * }}$, Hadi Nur ${ }^{b}$, Hasliza Bahruji ${ }^{c}$, Hartati ${ }^{\text {d }}$ \\ a Department of Chemistry, Faculty of science, Institut Teknologi Sepuluh Nopember (ITS), Kampus ITS Sukolilo, Surabaya 60111, Indonesia \\ b Ibnu Sina Institute for Scientific and Industrial Research, Universiti Teknologi Malaysia, 81310 UTM Skudai, Johor, Malaysia \\ c Cardiff Catalysis Institute, Cardiff University, CF10 3AT Cardiff United Kingdom \\ ' Department of Chemistry, Faculty of Science and Technology, Universitas Airlangga, Kampus UNAIR, Surabaya 60115, Indonesia \\ * Corresponding author: didikp@chem.its.ac.id
}

\section{Article history}

Submitted 5 January 2018

Revised 30 January 2018

Accepted 13 March 2018

Published Online 3 December 2018

\section{Graphical abstract}

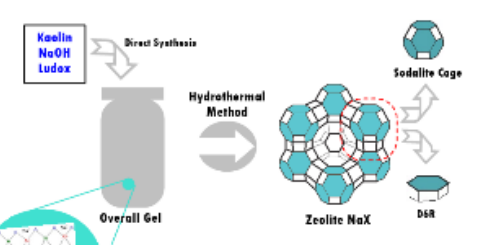

\begin{abstract}
The potential use of kaolin as silica and alumina precursor for the synthesis of zeolite $\mathrm{NaX}$ was investigated in this study. The synthesis involved three steps of reactions; the preparation of seed gel, the formation of feedstock gel using kaolin and the combination of overall gel followed by hydrothermal treatment at $105^{\circ} \mathrm{C}$ for 12 hours. Analysis using X-ray Diffraction (XRD) method indicated the transformation of kaolin into pure phase zeolite NaX with a small amount of kaolin was still visible. Detail microscopic analysis showed the morphology of zeolite $X$ consisted of octahedral particles with a crystallite diameter of 20-30 $\mu \mathrm{m}$. Analysis of surface acidity using pyridine as probe molecule indicated the zeolite $X$ has high Brǿnsted acidity with $0.181 \mathrm{mmol} / \mathrm{g}$ of acid sites, significantly higher than Lewis acidity $\sim 0.053 \mathrm{mmol} / \mathrm{g}$. The $\mathrm{N}_{2}$ adsorption-desorption measurement indicated a type IV material with both microporous and mesoporous structures with an average pore size of $1.47 \mathrm{~nm}$ for micropore and $3.41 \mathrm{~nm}$ for mesoporous.
\end{abstract}

Keywords: Kaolin, zeolite NaX, porous materials, hydrothermal method

\section{INTRODUCTION}

Zeolite consists of four connected $\mathrm{AlO}_{4}$ and $\mathrm{SiO}_{4}$ tetrahedrons connected via oxygen to form porous aluminosilicates framework. The intracrystalline channel in the zeolite framework is occupied with water molecule and cation to neutralise the negative charge of $\mathrm{AlO}_{4}$. The mobility of the cation and the flexibility of the size, shape and pore structure of the zeolite allows modification to accommodate catalytic desire. Zeolite is commonly produced from hydrogels aluminate and sodium silicate, however, production of zeolite from alternative silica and alumina source such as bagasse fly ash [1] [2], rice hush ash [3] and kaolin [4] have received considerable attention since the past few decades. Kaolin is naturally occurring minerals that abundantly available in Indonesia particularly in south Sumatra, Bangka Belitung and Java island. Kaolin from Bangka Belitung has low iron and titanium content but rich with silica (54.9 wt.\%) and alumina (36 wt.\%). Studies were previously carried out for the synthesis of zeolite $\mathrm{X}$ using kaolin originated from Bulgaria [5] and also the synthesis of zeolite $Y$ from natural kaolin [6], kaolin obtained from China [7] and Iran [8]. Kaolin is an ideal alternative candidate to replace commercial silica and alumina precursors due to a high level of silica and alumina with relatively low iron content. The use of kaolin as raw material for the synthesis of zeolite offers an alternative economical route by utilising naturally abundant resources rather than commercially available chemical.

The aim to synthesis zeolite $\mathrm{NaX}$ is due to its unique threedimensional pore structure and surface acidity that can be utilised as a solid acid catalyst [9], ion exchanger [10], and adsorbent. Zeolite $\mathrm{NaX}$ belongs to faujasite family that composes of sodalite cage with 6-rings (D6R) to form hexagonal framework.

Studies that were carried out on the synthesis of zeolite $\mathrm{X}$ from kaolin required acid or base leaching treatment to reduce its resistance towards chemical transformation to zeolite [11]. Kaolin also required thermal treatment at high temperature $\sim 700-900^{\circ} \mathrm{C}$ to form amorphous metakaolin before it can be used for zeolite synthesize [12]. The additional pre-treatment process has an indirect effect on the production cost and also detrimental to the environment i.e., production of greenhouse gases.

Here we investigate the potential of kaolin as alternative silica and alumina precursors without the need for pre-treatment to produce zeolite $\mathrm{NaX}$ via hydrothermal method. The physical properties of zeolite $\mathrm{X}$ were analysed using XRD, SEM, FTIR and $\mathrm{N}_{2}$-gas adsorption-desorption methods to obtain its crystal morphology, framework structure, pore structure and surface acidity.

\section{EXPERIMENTAL}

\section{Materials}

Kaolin from Bangka Belitung contained 36 wt. $\% \mathrm{Al}_{2} \mathrm{O}_{3}, 54.9$ wt.\% $\mathrm{SiO}_{2}, 3.34$ wt. $\% \mathrm{Fe}_{2} \mathrm{O}_{3}$ and 1.88 wt. $\% \mathrm{~K}_{2} \mathrm{O}$. The materials used in the synthesis were sodium hydroxide ( 99 wt.\% $\mathrm{NaOH}$ Merck), sodium aluminate (53 wt.\% $\mathrm{NaAlO}_{2}$ Merck), silica colloidal (LUDOX) (30 wt. $\% \mathrm{SiO}_{2}$ and 70 wt. $\% \mathrm{H}_{2} \mathrm{O}$ Merck), ammonium acetate (Merck) for ion exchanged and acidity characterization. Demineralized water was used for cleaning and chemical preparation.

\section{Synthesis of zeolite $\mathrm{NaX}$}

Bangka Belitung kaolin used in this study was obtained from Bangka Belitung (Sumatra, Indonesia). Chemical and mineralogical composition of the received kaolin is listed in Table 1. The as-received kaolin contains a low level of metal oxide impurities with Si to Al molar ratio of 1.53. Kaolin was used for the synthesis of zeolite $\mathrm{X}$ without prior pretreatment. The mixture kaolin and other precursors were 
dissolved in $\mathrm{NaOH}$ solution to produce amorphous $\mathrm{Si}$ and $\mathrm{Al}$ gel mixture which was then used for the hydrothermal synthesis of zeolite $\mathrm{X}$.

The synthesis of zeolite $\mathrm{NaX}$ was carried out following three steps; the preparation of seed gel, the production feedstock gel and the mixing of seed and feedstock gels to produce an overall gel. The seed gel $\left(\mathrm{Al}_{2} \mathrm{O}_{3} .4 \mathrm{SiO}_{2}\right)$ was prepared by the addition of the $\mathrm{NaAlO}_{2}$ dan silica colloidal mixture into $\mathrm{NaOH}$ solution. The mixture was stirred continuously to form a homogeneous mixture and was left to age for 24 $\mathrm{h}$ at room temperature. The feedstock gel $\left(\mathrm{Al}_{2} \mathrm{O}_{3} \cdot 4.3 \mathrm{SiO}_{2}\right)$ was also prepared following similar procedures but sodium aluminate was replaced by kaolin. The resulting feedstock gel was then added to the seed gel with the ratio of $18: 1$ in order to get overall synthesis gel mixture. The gel mixture was left to age for $24 \mathrm{~h}$ at room temperature before transferred into Teflon line vessel and hydrothermally treated at $105^{\circ} \mathrm{C}$ for $12 \mathrm{~h}$. The simplified synthesis process was illustrated in the schematic diagram in Fig.1.
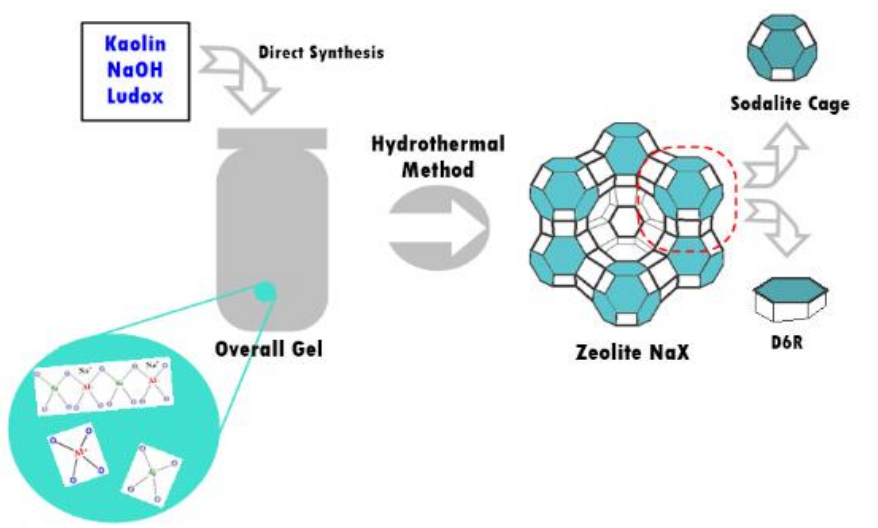

Fig. 1 The schematic diagram for the synthesis of zeolite NaX from kaolin.

The resulting powder was washed thoroughly with distilled water until the $\mathrm{pH}$ of the supernatant was neutral. The powder was then dried and calcined under an air flow at $500^{\circ} \mathrm{C}$ for $1 \mathrm{~h}$ at $2 \% \mathrm{~min}$ ramp rate. The synthesised zeolite $\mathrm{NaX}$ was ion-exchanged with $\mathrm{NH}_{4}{ }^{+}$by mixing the resulting powder with ammonium acetate to form $\mathrm{NH}_{4} \mathrm{X}$, as shown in the following equation (1)(2).

$$
\begin{aligned}
& \mathrm{NaX}+\mathrm{CH}_{3} \mathrm{COONH}_{4} \rightarrow \mathrm{NH}_{4} \mathrm{X}+\mathrm{CH}_{3} \mathrm{COONa} \\
& \mathrm{NH}_{4} \mathrm{X} \rightarrow \mathrm{HX}+\mathrm{NH}_{3}
\end{aligned}
$$

The $\mathrm{NH}_{4} \mathrm{X}$ was then calcined at $550^{\circ} \mathrm{C}$ for 5 hours to form $\mathrm{H}$-zeolite $\mathrm{X}$ framework.

\section{Characterization of synthesized zeolite $\mathrm{NaX}$}

$\mathrm{X}$-ray Fluorescence was used to obtain chemical composition of Kaolin. The synthesized NaX powder and kaolin were also characterised using X-ray Diffraction (XRD) Philip Expert with CuKa $(\lambda=1.5405 \AA)$ radiation to determine the crystalline phase and crystallinity. Data were recorded in the range of $5-40^{\circ}$ with a step size of $0.02^{\circ}$. The infrared spectra of $\mathrm{NaX}\left(\mathrm{SiO}_{2} / \mathrm{Al}_{2} \mathrm{O}_{3}\right.$ ratio $\left.=4\right)$ was recorded using Fourier Transform Infrared spectrophotometer (8400S Shimadzu) with $\mathrm{KBr}$ pellet method. Sample and $\mathrm{KBr}$ were mixed with the ratio of 1:99, crushed and molded into a pellet, then compressed using hydraulic pressure. The formed pellet was placed on the holder and recorded in 4000-400 $\mathrm{cm}^{-1}$.

The morphology of the synthesis zeolite $\mathrm{X}$ was analysed using Scanning Electron Microscopy (SEM) ZEIS EVO MA 10 FT-IR. Prior to the analysis, the sample was placed on a carbon tape and coated using $\mathrm{Pd} / \mathrm{Au}$ for 15 minutes at $6 \times 10^{-2} \mathrm{mBar}$ pressure, then scanned to analyse the sample morphology.

Nitrogen adsorption-desorption isotherms were observed using the Quantachrome Corporation (Nova-1200) instrument. Prior to the analysis, 0.2 gram of sample was placed in the vacuum for 3 hours at
$300{ }^{\circ} \mathrm{C}$ to evacuate adsorbed water, the sample was then exposed to nitrogen gas at $77 \mathrm{~K}$. The specific surface area $\left(\mathrm{S}_{\mathrm{BET}}\right)$ is calculated using BET (Brunauer-Emmet-Teller) equation. The total pore volume was obtained based on the amount of nitrogen adsorbed at $\mathrm{P} / \mathrm{P}_{\mathrm{o}} 0-0.99$, while the pore size distribution was analyzed using BJH (Barret-JoinerHalenda). The micropore size distribution was analysed using SF (Saito-Foley) method

Pyridine was used as a probe molecule for acidity studies. The sample was weight $\sim 10 \mathrm{mg}$ and pressed to form a thin and transparent film. The film was then placed in the sealed sample holder and annealed in a tubular furnace under vacuum at $300{ }^{\circ} \mathrm{C}$ for 3 hours. The film was cooled at $30{ }^{\circ} \mathrm{C}$ before exposed with pyridine. The temperature was increased to $150{ }^{\circ} \mathrm{C}$ to remove physisorbed pyridine on the surface. The chemical adsorption of pyridine on the zeolite $\mathrm{X}$ was measured using FTIR and the adsorbed pyridine peak was determined using the Gaussian method.

\section{RESULTS AND DISCUSSION}

\section{Characterisation of zeolite $\mathrm{NaX}$}

Detail chemical composition of kaolin obtained from XRF analysis was summarised in Table 1 . Kaolin predominantly consisted of $\mathrm{SiO}_{2}$ and $\mathrm{Al}_{2} \mathrm{O}_{3}$ at $\sim 91$ wt. \% with the impurities consisted of $\mathrm{K}_{2} \mathrm{O}$, $\mathrm{Fe}_{2} \mathrm{O}_{3}$, and traces of metal oxides. Considering the low level of metal oxide impurities, kaolin was used without prior pre-treatment for the synthesis of zeolite X. We provide EDX analysis of the as-synthesised zeolite $\mathrm{X}$ that indicated the $\mathrm{NaX}$ consisted of siliconnium and oxygen as main elements for zeolite framework with sodium that presumably as stabilizer cation (Fig. 2). We imply that metal oxide impurities that were originally present in kaolin were successfully evacuated from the reaction mixture. The evacuation occurred during the dissolution of kaolin with sodium hydroxide followed by thorough washing with deionised water and air calcination at high temperature.

Table 1 Minerals analysis by XRF for Kaolin.

\begin{tabular}{cc}
\hline Minerals & Wt. \% \\
\hline $\mathrm{Al}_{2} \mathrm{O}_{3}$ & 36 \\
$\mathrm{SiO}_{2}$ & 54.9 \\
$\mathrm{P}_{2} \mathrm{O}_{5}$ & 0.88 \\
$\mathrm{~K}_{2} \mathrm{O}$ & 2.88 \\
$\mathrm{CaO}$ & 0.58 \\
$\mathrm{TiO}_{2}$ & 0.551 \\
$\mathrm{~V}_{2} \mathrm{O}_{5}$ & 0.03 \\
$\mathrm{Fe}_{2} \mathrm{O}_{3}$ & 3.37 \\
$\mathrm{CuO}_{\mathrm{Rb}} \mathrm{O}$ & 0.097 \\
$\mathrm{ZnO}$ & 0.18 \\
$\mathrm{NiO}$ & 0.02 \\
\hline
\end{tabular}

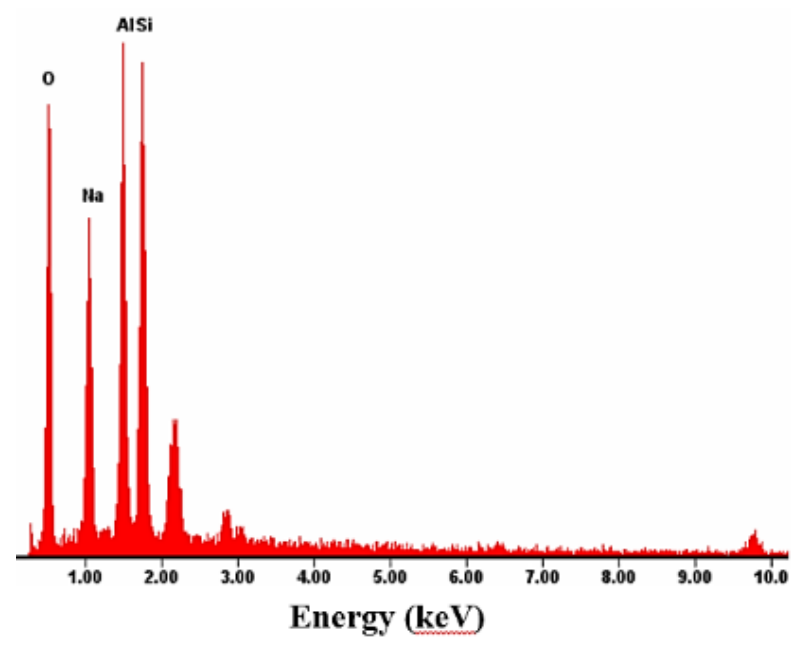

Fig. 2 EDX analysis on the elemental composition of synthesized $\mathrm{NaX}$ 
In order to synthesis zeolite $\mathrm{NaX}$ with high crystallinity and purity, the synthesis condition should be carefully controlled including the purity of the precursors. The hydrothermal treatment requires optimisation of synthesis condition by controlling the temperature and the crystallisation time. Variation of the molar ratio of starting materials significantly determined morphology, surface area and acidity of the synthesized zeolite. Davis [13] reported that controlling the temperature of hydrothermal treatment affected the nucleation and crystal growth of zeolite. In general, hydrothermal synthesis at high temperature produced high thermal energy that consequently shortened the crystallization time. However, synthesis at high temperature often produced large aggregates of zeolite. We found the optimum crystallization temperature for the synthesis of zeolite $\mathrm{NaX}$ from kaolin was achieved at $105^{\circ} \mathrm{C}$. Detail analysis of the morphological structure and the purity of the synthesized zeolite was analysed using XRD and infrared spectroscopy.

X-ray diffractogram of kaolin, synthesised zeolite $\mathrm{NaX}$ and commercial zeolite $\mathrm{NaX}$ were shown in Fig 3 . The peaks corresponded to kaolin at $20^{\circ}, 20.5^{\circ}, 22^{\circ}, 35^{\circ}, 36^{\circ}, 39^{\circ}$ and $40^{\circ}$ were significantly reduced in the as-synthesised zeolite $\mathrm{NaX}$. The diffractogram pattern of zeolite $\mathrm{NaX}$ synthesised using kaolin showed peaks at $2 \theta=6.15 ; 10.02$ $23.28 ; 26.64 ; 31.95^{\circ}$ which were identical to the peaks appeared in standard zeolite X [13]. The XRD pattern of synthesized zeolite NaX was also in accordance with the peaks of $\mathrm{NaX}$ according to International Zeolite Association (IZA)[14]. However, two peaks corresponded to kaolin at $13^{\circ}$ and $25^{\circ}$ were still present but at significantly low intensity in zeolite $\mathrm{NaX}$ which suggested incomplete dissolution of kaolin with sodium hydroxide during the preparation of gel mixture.

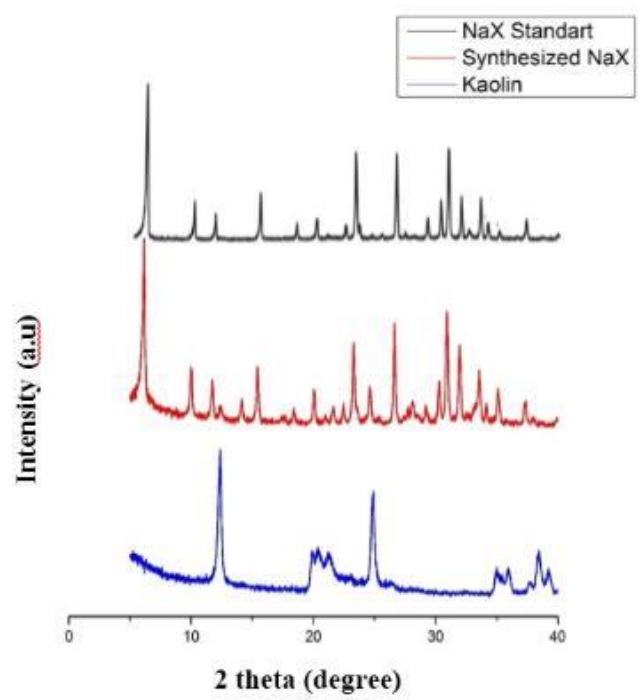

Fig. 3 The XRD pattern of NaX commercial standard, synthesize NaX and kaolin.

The synthesized zeolite $\mathrm{NaX}$ was also analysed using infrared spectroscopy to provide spectroscopic evidence on the structure and the functional group of zeolite X. The IR spectra of zeolite X was also compared to kaolin as shown in Fig.4. The presence of a band at 1107 $\mathrm{cm}^{-1}$ in the infrared analysis of kaolin indicated the stretching vibration of tetrahedral $\mathrm{SiO}_{4}$ and $\mathrm{AlO}_{4}$. The peak appeared at $1029 \mathrm{~cm}^{-1}$ is corresponded to the vibration of $\mathrm{Si}-\mathrm{O}-\mathrm{Si}$ ( $\mathrm{Si}-\mathrm{O}-\mathrm{Si}$ in-plane stretching). The vibration of Al-O-H appeared at $913 \mathrm{~cm}^{-1}$ which subsequently disappeared in $\mathrm{NaX}$ spectra. The characteristic bands of $\mathrm{NaX}$ which consisted of FAU type structure occurred between 1250-950 $\mathrm{cm}^{-1}[15]$ which showed external asymmetric stretching of $\mathrm{TO}_{4}$, where $\mathrm{T}$ is $\mathrm{Si}$ or $\mathrm{Al}$. The band appeared at $790-650 \mathrm{~cm}^{-1}$ is external vibration associated with the sensitive tetrahedral structure of zeolite $\mathrm{X}$ (external symmetric vibration). This is a typical vibration that appears in most silica materials [16]. Asymmetric stretching and symmetric stretching of synthesized $\mathrm{NaX}$ can be seen occurred at $977.94 \mathrm{~cm}^{-1}$ and $744.55 \mathrm{~cm}^{-1}$. The specific $\mathrm{TO}_{4}(\mathrm{~T}=\mathrm{Si}$ or $\mathrm{Al})$ vibrational peak for zeolite was identified by band appeared at $451 \mathrm{~cm}^{-1}$. The peak observed at $561 \mathrm{~cm}^{-}$
${ }^{1}$ was identified as vibrational of D6R rings that distinguished zeolite $\mathrm{X}$ structure with another aluminosilicate zeolite. The spectroscopic evidence obtained from the infrared analysis further consolidate the formation of zeolite $\mathrm{X}$ crystal structure that was synthesised using that kaolin as silica and alumina precursor.

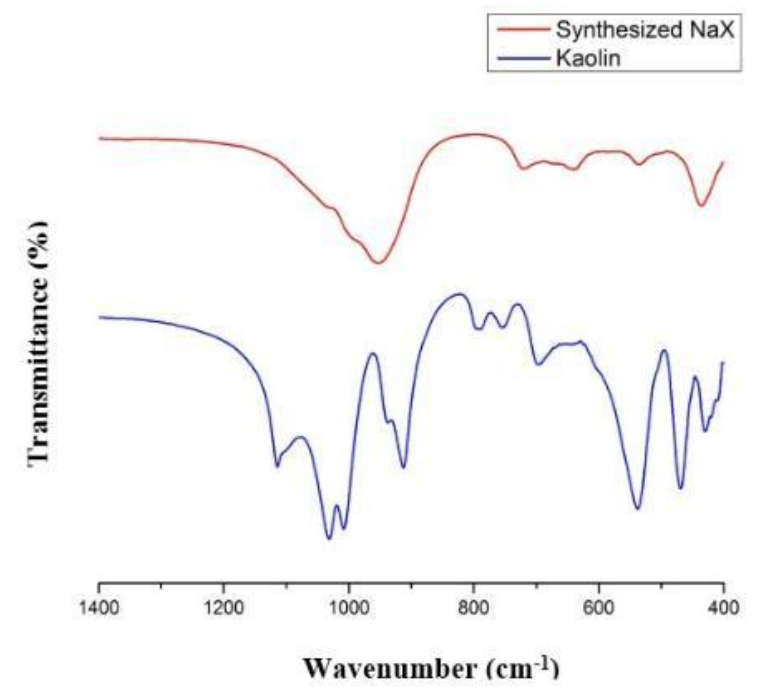

Fig. 4 The Spectra FTIR of synthesized NaX and kaolin.
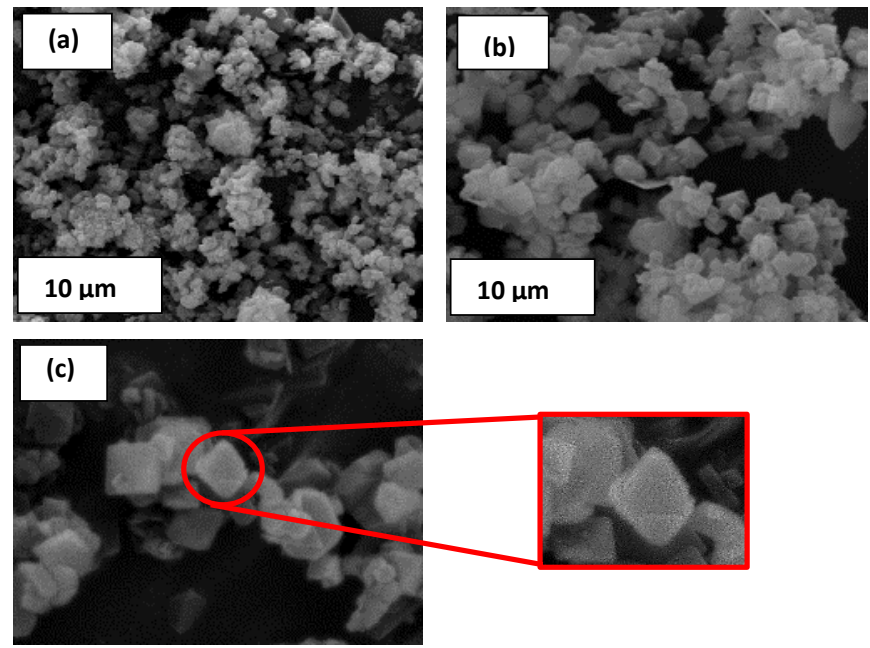

Fig. 5 The SEM micrograph of synthesized $\mathrm{NaX}$.

The morphology and crystallite size of the synthesised material was analysed using Scanning Electron Microscopy (SEM). Fig. 5 shows the morphology of $\mathrm{NaX}$ which appears as a hexagonal structure with average crystallite size $\sim 10-20 \mu \mathrm{m}$. This is a typical morphology for zeolite X which were observed previously by others [17] [18]. SEM images also show the $\mathrm{NaX}$ crystallite was in uniform aggregate size and some crystallite agglomerates to form large aggregates. The presence of remaining kaolin as a result of incomplete dissolution which was indicated by XRD analysis was observed as a thin layer occurs around the NaX crystallite. The incomplete dissolution of kaolin also affected the $\mathrm{Si} / \mathrm{Al}$ ratios of the synthesised zeolite $\mathrm{X}$. The EDX analysis shown Fig. 2 indicated that the zeolite $\mathrm{X}$ was consisted of $23 \mathrm{wt} \%$ of Si and 18 $\%$ of $\mathrm{Al}$ to give the $\mathrm{Si} / \mathrm{Al}$ ratio of 1.28 . This is significantly lower than the experimental value which also suggested incomplete dissolution of kaolin during the synthesis.

The specific surface area of kaolin and zeolite $X$ were analysed using BET method with the nitrogen adsorption-desorption profile provides information on the type of pore of zeolite (Fig. 6). Kaolin showed no nitrogen adsorption at relative pressure, $\mathrm{P} / \mathrm{P}_{\mathrm{o}}$ within $0.1-0.3$ which indicated the type II non-porous material. The non-porous kaolin also has a very low surface area of $\sim 14 \mathrm{~m}^{2} / \mathrm{g}$. The transformation of 
kaolin to zeolite $X$ resulting in a high surface area $\left(80 \mathrm{~m}^{2} / \mathrm{g}\right)$ material that is beneficial for research and industrial purposes. The assynthesised zeolite HX showed an isotherm type IV which indicated the presence of mesoporous structure within the framework.

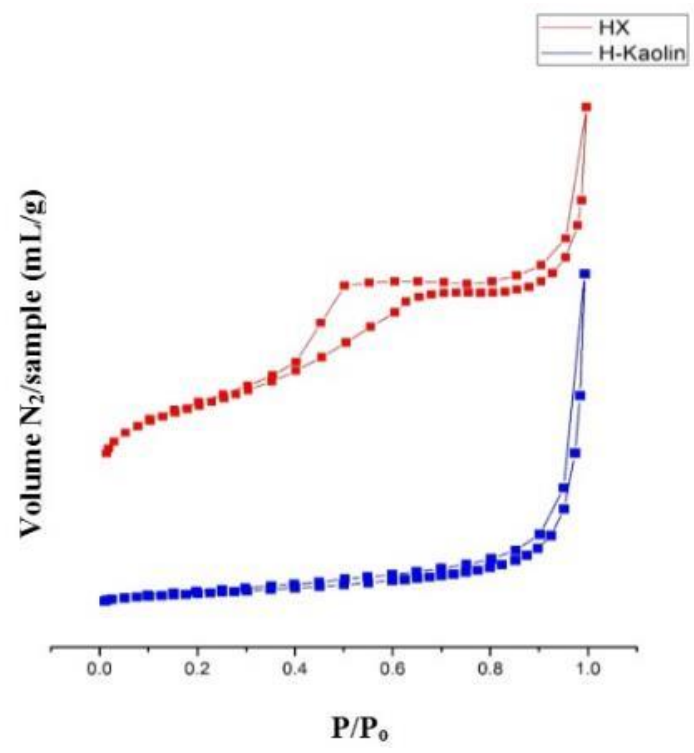

Fig. 6 The Isotherm $\mathrm{N}_{2}$ Adsorption-Desorption of $\mathrm{HX}$ and H-kaolin.

The isotherm $\mathrm{N}_{2}$ profile of $\mathrm{HX}$ exhibited an increasing nitrogen molecule adsorption at low relative pressure ( 0 to 0.3$)$ corresponding to the adsorption occurred to fill the micropores of zeolite. At $\mathrm{P} / \mathrm{P}_{\mathrm{o}}$ of 0.3 , the surface of zeolite $\mathrm{X}$ was covered by a monolayer nitrogen molecule. Adsorption of nitrogen to the zeolite surface was continuously increased at $\mathrm{P} / \mathrm{P}_{\mathrm{o}} \sim 0.4-0.7$, which indicated the nitrogen adsorption on the uniform slit-shaped intracrystal mesopore. The surface of the pore only allowed a limited layer of adsorbate, its called condensation and causing the hysteresis loop. Hysteresis loop was observed at $\mathrm{P} / \mathrm{P}_{\mathrm{o}} 0.4$ 1 , occurred due to the desorption of nitrogen.

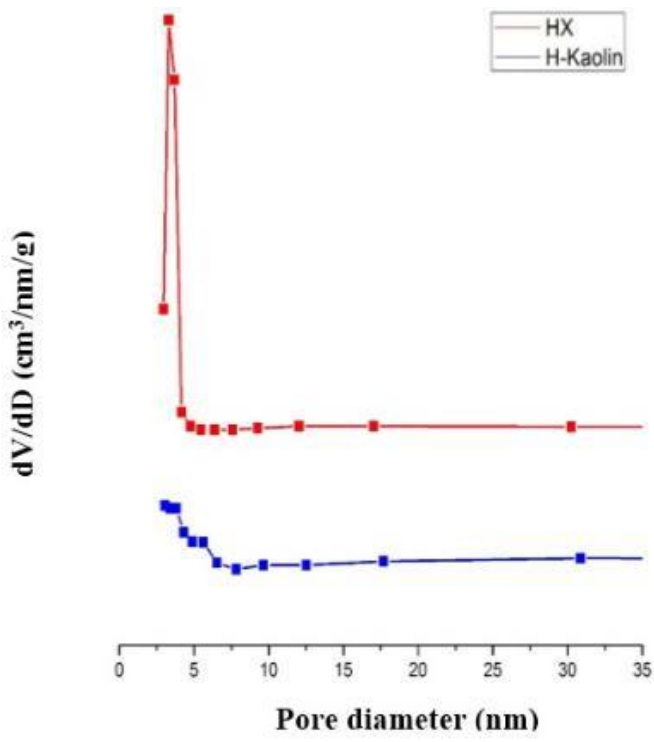

Fig. 7 The pore size distribution of kaolin and synthesized $\mathrm{HX}$ from BJH (Ballet, Joiner, Halenda) method.

Analysis of the pore size distribution using the BJH (Barret, Joiner, Halenda) method in Fig. 7 showed the presence of meso-sized pore type structure $\sim 2-5 \mathrm{~nm}$ in diameter with a peak centered at $3.4 \mathrm{~nm}$. It implies that the zeolite $\mathrm{NaX}$ consisted of the intra-crystal mesoporous structure with narrow and sharp pore distribution. We also compare the pore size distribution of zeolite $\mathrm{NaX}$ with the raw material kaolin that showed no significant pore structure can be observed in kaolin. This is in agreement with the $\mathrm{N}_{2}$ adsorption-desorption analysis that revealed type II isotherm corresponded to the non-porous structure of kaolin. The formation of mesopores within the zeolite $\mathrm{NaX}$ structure is rather surprising due to in general the synthesis of mesoporous zeolite requires the presence of surfactant as structure directing agent. We suggested the formation of mesoporous structure is due to the arrangement of silica and alumina in the slit-pore of zeolite $\mathrm{NaX}$. Apart from the presence of mesopores, analysis of zeolite NaX SF method as shown in Fig. 8 also indicated the presence of the microporous structure. The micropore size distribution showed the highest pore diameter of $\sim 1.47$ $\mathrm{nm}$ with a micropore volume of $\sim 0.006 \mathrm{~cm}^{3} / \mathrm{g}$ contrary to kaolin that only consisted of relatively small micropore size within 0.36 and 0.90 $\mathrm{nm}$ of diameter.

The surface acidity was performed by infrared spectroscopy using pyridine as a probe molecule. The amount of adsorbed pyridine on the zeolite $\mathrm{NaX}$ was analysed in the $1700-1400 \mathrm{~cm}^{-1}$ of wavelength region. Protonated pyridine molecule in the form of pyridium ion $\left(\mathrm{C}_{5} \mathrm{H}_{5} \mathrm{NH}^{+}\right)$ interacting with Brónsted acid sites shows a specific adsorption band at a wavenumber of $\sim 1540-1545 \mathrm{~cm}^{-1}$. The pyridinium ion is a result of bond formation between pyridine with a proton from the surface hydroxyl group of zeolite X. Interaction between pyridine with Lewis acid site on the surface formed by coordinated bonding interaction between the free electron pairs of pyridine molecule with the empty orbital of extra -framework alumina in the zeolite. This interaction leads to the appearance of the absorption band at wavenumber $\sim 1440-1452$ $\mathrm{cm}^{-1}[19]$.

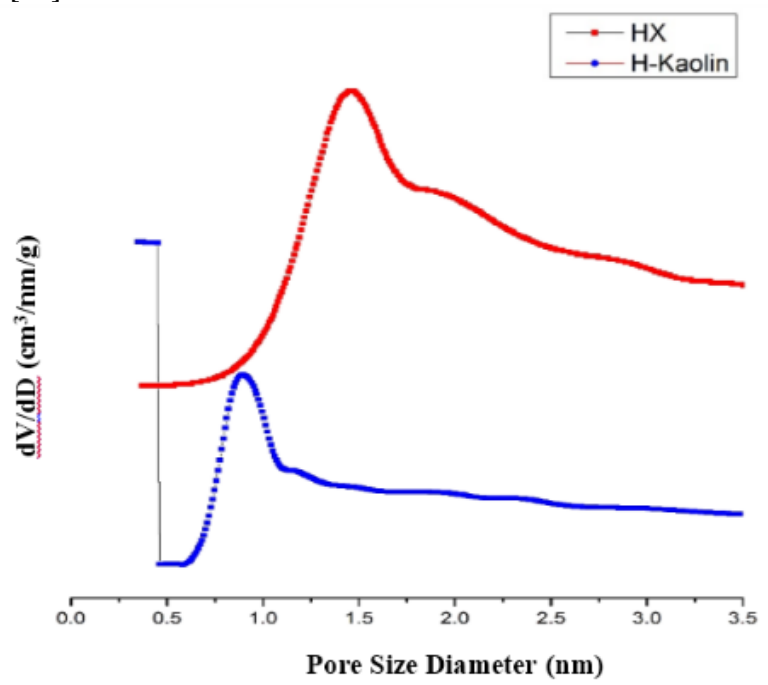

Fig. 8 The micropore distribution of as-synthesized HX from the SF method

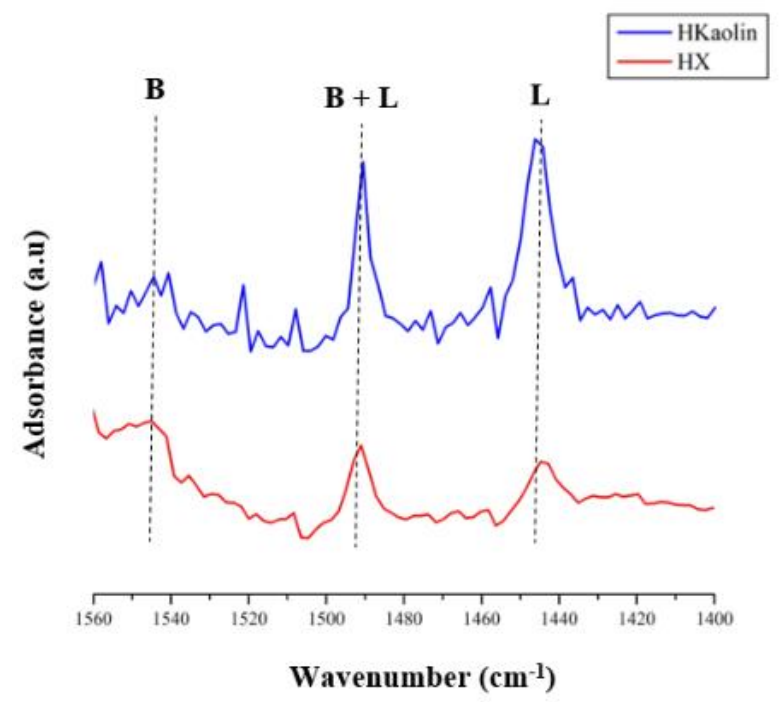

Fig. 9 The infrared spectra of pyridine adsorption of synthesized HX 
The infrared spectra of the pyridine upon adsorption on zeolite HX showed pyridine peak vibration appeared $\sim 1440-1452 \mathrm{~cm}^{-1}$ indicating the presence of Lewis acidity. The band appeared at $1545 \mathrm{~cm}^{-1}$ revealed Brǿnsted acidity and the band at $1490 \mathrm{~cm}^{-1}$ corresponded to the total adsorption of pyridine on both Lewis and Brǿnsted acid sites [20]. The peak area of adsorbed pyridine was determined using the Gaussian method to indicate the amount of surface acid site on the as-synthesised zeolite $\mathrm{X}$. The calculated data showed the zeolite $\mathrm{X}$ has a high number of Brǿnsted acidity in comparison to Lewis acidity to give about $\sim 0.18$ $\mathrm{mmol} / \mathrm{g}$ of the Brǿnsted acid site and $0.05 \mathrm{mmol} / \mathrm{g}$ of Lewis acid site.

\section{CONCLUSION}

We investigated the potential use of abundantly available silica and alumina riched kaolin to be transformed into zeolite $\mathrm{X}$. The synthesis occurs in three steps involving the preparation of seed gel, the formation of feedstock gel using kaolin and the mixture of these two gels to form the overall gel. The crystallization process was carried out under a hydrothermal condition at $105^{\circ} \mathrm{C}$ which produced zeolite $\mathrm{NaX}$ with both microporous and mesoporous structure. The zeolite $\mathrm{NaX}$ also consisted of high purity and crystallinity with high surface acidity which ideal as a catalyst in many catalytic applications.

\section{ACKNOWLEDGEMENT}

The authors would like to acknowledge the Ministry of Research and Higher Education, Indonesia, under "PBK" Research 2017-2019 with contract number of 525/PKS/ITS/2017.

\section{REFERENCES}

[1] S. Chandrasekhar, P.N. Pramada, Investigation on Synthesis of Zeolite NaX from Kerala Kaolin, Journal of Porous Materials (2004) 6:283-297.

[2] Y. Liu, C. Yan, X. Qiu, D. Li, H. Wang, A.Alshameri, Preparation of Faujasite Block from Fly Ash-Based Geopolymer via in-Situ Hydrothermal Method, Journal of the Taiwan Institute of Chemical Engineers 433-39 (2016) 59.

[3] R.M. Mohamed, I.A. Mkhalid, M.A. Barakat, Rice husk ash as a renewable source for the production of zeolite $\mathrm{NaY}$ and its characterization, Arabian Journal of Chemistry 48-53 (2012) 8.
[4] J.-Q.Wang, Y.-X. Huang, Y. Pan, Hydrothermal Synthesis of High Purity Zeolite A and $\mathrm{X}$ from Natural Kaolin without Calcination Microporous and Mesoporous Materials 50-56 (2014) 199.

[5] C. Belviso, F. Cavalcante, A. Lettino, S. Fiore, A and X-Type Zeolites Synthesised from Kaolinite at Low Temperature, Applied Clay Science 162-68 (2013) 80-81.

[6] J-Q. Wang, Y. Pan, New Hydrothermal Route for the Synthesis of High Purity Nanoparticles of Zeolite X from Kaolin and Quartz, Microporous and Mesoporous Material 77-85 (2016) 232.

[7] Y. Ma, C. Yan, A. Alshameri, X. Qiu, D. Li, C. Zhou, Synthesis and Characterization of $13 \mathrm{X}$ Zeolite from Low-Grade Natural Kaolin, Advanced Powder Technology 495-99 (2014) 25.

[8] V. Garshasbi, M. Jahangiri, M. Anbia, Equilibrium CO2 Adsorption on Zeolite 13X Prepared from Natural Clays, Applied Surface Science 22533 (2017) 393.

[9] K.-H.Chung, D.-R. Chang, B.-G. Park, Removal of Free Fatty Acid in Waste Frying Oil by Esterification with Methanol on Zeolite Catalysts, Bioresource Technology 38-43 (2008) 99.

[10] K.M. Roghayeh, S.A. Fakhry, Study on the Thermal Behavior of Low Silica X-type Zeolite Ion Exchanged with Alkaline earth Cation, Microporous and Mesoporous Material 285-293 (2009) 120.

[11] Z. Xu, T. DaQing, Z. JingJing, L. XingYang, Synthesis of NaX Zeolite at Room Temperature and Its Characterization, Material Letters 80-83 (2013) 104.

[12] W. Jin-Quan, H. Ya-Xi, P. Yuanming, X. Jin, Hydrothermal Synthesis of High Purity Zeolite A from Natural Kaolin without Calcination, Microporous and Mesoporous Material 50-56 (2014) 199.

[13] M. Davis, Zeolite and Molecular Sieve Synthesis, Chemistry Material 756-768 (1992) 4.

[14] C.W.Purnomo, C.Salim, H. Hinode, Synthesis of Pure Na-X and Na-A Zeolite from Bagasse Fly Ash, Microporous and Mesoporous Materials, 6-13 (2012) 162.

[15] W. Mozgawa, M. Krol, Barczyk, FTIR Studies of Zeolites from Different Structural Groups, CHEMIK 667-674 (2011) 65.

[16] D. Chen, X. Hu, L. Shi, Q. Cui, H. Wang, H. Yao, Synthesis and Characterization of Zeolite X from Lithium Slag, Applied Clay Science 148-51 (2012) 59-60.

[17] J.M. Gómez, E. Diez, I. Bernabé, Deoxygenation of M-Toluic Acid over Hierarchical X Zeolite, Catalysis Communications 55-58 (2016) 78.

[18] H.J. Lee, Y.M. Kim, O.S.Kweon, I.J. Kim, Structural and Morphological Transformation of NaX Zeolite Crystals at High Temperature, Journal of the European Ceramic Society 561-64 (2007) 27.

[19] K.A. Layman, M.M. Ivey, J.C. Hiemminger, Pyridin Adsorption and Acid/Base Complex Formation on Ultrathin Films of $\gamma-\mathrm{Al}_{2} \mathrm{O}_{3}$ on $\mathrm{NiAl}$ (100), Journal Physic Chemistry 8538-8546 (2003) 107.

[20] S.Bendenia, I. Batonneu-Gener, J. Camparot, K. Marouf Khelifa, H. Hammoudi, A. Khelifa, Acidity Study of X Zeolites Modified by Nickel And/or Chromium Cations in the Case of Binary and Ternary Exchanges, Microporous and Mesoporous Materials 111-18 (2012) 159. 